\title{
From the Perspective of Commercial Banks to Explore the Difficulties in the Development of the "Time Bank" Mutual Support
}

\author{
Danke Liu \\ Anhui University of Finance and Economics, Bengbu, China \\ Email: LiuDanke@163.com
}

How to cite this paper: Liu, D. K. (2020). From the Perspective of Commercial Banks to Explore the Difficulties in the Development of the "Time Bank" Mutual Support. Open Journal of Business and Management, $8,1243-1251$.

https://doi.org/10.4236/ojbm.2020.83080

Received: April 21, 2020

Accepted: May 24, 2020

Published: May 27, 2020

Copyright $\odot 2020$ by author(s) and Scientific Research Publishing Inc. This work is licensed under the Creative Commons Attribution International License (CC BY 4.0).

http://creativecommons.org/licenses/by/4.0/

\begin{abstract}
"Time Bank", as the most representative form of mutual support for the aged, is still in the early stage in China. From the perspective of commercial banks, this paper explores how time currency operates and analyzes the real dilemma of "Time Bank" from four main factors including time account, time currency, time deposit receipt, free deposit and withdrawal, thus providing effective reference for "Time Bank" to obtain credibility and expand coverage in order to form a far-reaching pension mode finally.
\end{abstract}

\section{Keywords}

Commercial Banks, Time Bank, Mutual Support for the Aged, Time Currency

\section{An Overview of Mutual Support for the Aged}

\subsection{Connotations and Characteristics of Mutual Support}

Mutual pension mode is a new type of pension mode which refers to a new type of pension mode that achieves mutual benefit for the elderly group through mutual support and spiritual comfort between the elderly groups and other groups. Generally speaking, the elderly are not consumers in the mutual support mode, and mutual support for the aged can make the elderly to participate in social affairs more, especially that the healthy young elderly can play their role well in the mode. If everyone can view natural aging in a positive way, and the elderly can achieve self-worth in the later life, the aging problem will not threaten the normal operation way of the society and healthy development of the economy (Chen, 2020).

Mutual support for the aged has the following outstanding features. First, mu- 
tual support mode is designed for the elderly to enhance the sense of social participation so it emphasizes the main role of the elderly groups. Although other groups can also participate, it mainly focuses on the elderly groups. Second, mutual assistance is the essential of the whole mechanism. Mutual support for the aged can avoid many drawbacks of the traditional endowment pattern, the most important one of which is to encourage them to play their roles in the daily life, and their spiritual needs and material needs all can be meet by mutual assistance, and it emphasizes that the elderly are not only consumers, but also participants. Third, the main aid pattern is not medical aid but living aid. Most of the current mutual aid modes provide convenience and help for the daily life of the elderly, including shopping, housework, chatting, etc. (Chen, 2020). As far as the health problems and medical needs of the elderly are concerned, the mode cannot directly provide professional help, but still ask professional medical institutions for help if the elderly have health problems.

\subsection{Problems Existing in Mutual Support for the Aged}

\subsubsection{Lack of Relevant Laws and Regulations}

Although the mode of mutual support for the aged has been widely recognized from the perspective of system design and has been practiced and popularized in many regions of China, there is still no clear standard for mutual support for the aged as well as no clear legal provisions to protect the life safety and property safety of the elderly due to differences in local region with various economy level, culture and resources.

\subsubsection{Difficult Risk Prevention and Control}

Due to the unstable health status of the elderly group, it is inevitable to bring potential safety hazard in the process of mutual assistance. Once an accident happens, it will cause harm to the elderly and also has a bad social impact. The voluntary mode does not constitute labor contract relationship so there are great difficulties in dividing the accident responsibility. In addition, both parties of mutual aid are likely to be the elderly so they have high safety risks in daily life.

\subsubsection{Low Social Degree of Recognizing}

Although the mode of mutual support for the aged has received a lot of favorable comments and promotion in the past two years, it has not been widely accepted in China. Because of the profound influence of traditional filial piety culture on people, the elderly and their children often do not accept the mode which asks strangers to care for the elderly. In China, the idea of "supported by the son" has far-reaching influence so it is difficult for all parties in society to accept this innovative endowment mode in a short period of time. The elderly may feel that their children would like to shirk responsibility, and responsible children may also have various worries about this mode.

\subsubsection{Incomplete Supporting Facilities for Old-Age Service}

Compared with the huge number and growth rate of the elderly group, the facil- 
ities for senior citizens in China are not perfect. Although governments at all levels in China have increased financial and material investment in recent years, and the construction of pension infrastructure and the level of pension security have been improved to a certain extent, at present, the construction of pension service facilities in many regions still have so many problems and cannot fully meet the pension needs of the elderly.

\section{An Overview of China's "Time Bank" Mutual Support}

\subsection{Exploration and Development of "Time Bank" in China}

"Time Bank" originated in the United States when the country was facing the severe aging problem, and its concept and operation way mainly came from the community mutual-support mode carried out by western countries since the 1980s. And China's "Time Bank" appeared in Shanghai in the late 1990s firstly. The Jinyang Neighborhood Committee of Tilanqiao Street, Hongkou District, Shanghai took the lead in establishing the "Time Bank" in 1998, organizing the young old to serve as volunteers. The accumulated service time can be used to exchange for the pension services when they need in the future. In 1999, an organization similar to "Love Time Bank" was set up in the residential area of Guangzhou Shouxing Mansion to help the healthy aged store time for themselves. In 2019, Nanjing, as the first city to implement unified policies at the city level, will realize deposit and withdrawal anywhere in Nanjing.

A total of 12 districts, 24 streets and 247 communities in Nanjing participated in the "Time Bank". Under the requirements of "unified management, unified standards and unified platform", the bank has established a series of Time Bank policy support systems, a set of Time Bank operation system, an integrated Time Bank information system and a series of Time Bank funding guarantee mechanisms. The unified "Time Bank" system built in Nanjing city has pushed this mode to a new climax, which means that this mode of mutual support is being perfected in a bold attempt and gradually recognized by the public.

\section{2. "Time Bank" System Connotation}

\subsubsection{Time Account}

Time account is an account system that records, stores and pays the value created by people's labor. Similar to traditional banks, time account also covers the basic information such as the account holder, ID card number, account number, etc. Time Bank creates personal or family time accounts based on user information and service information, with time as access subject and time voucher as access basis (Li et al., 2020). Time Bank supports account settlement of all users' transactions at various times and supports payment or transfer between users. Users can independently publish service requirements or time requirements through their exclusive time accounts, while other users can provide services or transfer funds through their own time accounts. This can not only meet the current service demand, but also save service time for the future poten- 
tial demand of oneself or family members. In view of the importance of time accounts, Time Banks must formulate fair scoring and assessment standards, service time storage and withdrawal mechanisms, establish a user information platform, and uniformly manage all users' personal information and service information.

\subsubsection{Time Currency}

Time is the one and only monetary form of "Time Bank" and all values are measured by the length of time. However, the duration is not simply equivalent to the service time, but depends more on the service attitude and quality. The user satisfaction is taken as the standard to measure the duration, too. A high customer satisfaction can increase the duration on the basis of the actual duration, while low customer satisfaction can deduct the duration from the actual duration or even be negative. "Time Bank" does not have real currency transactions as all transfers, deposits and withdrawals only involve time currency. And the main purpose of providing labor services is also to exchange time.

\subsubsection{Time Deposit Receipt}

Time deposit receipt is information vouchers that record the service duration, service quality, and customer satisfaction as the basis for consideration when users provide labor services each time. Time currency mainly represents the value of time. After the user pays the service time, the bank stores the new time currency in time according to the corresponding standard, and records it in detail on the time deposit certificate, which will be used as the basis for future withdrawal. Through the time deposit certificate, users can freely access the service time, which is not only the authoritative confirmation of the labor value created by the Time Bank, but also the effective proof used by users to obtain the served time in the future. Therefore, time deposit certificates are the basic guarantee for users to deposit and withdraw when they are in need. In addition, the time deposit certificate is also a certificate for users to earn interest on deposit. Based on the amount and duration of time saved, the Time Bank regularly issues interest on deposit to users like ordinary commercial banks, and the interest is also measured in time currency.

\subsubsection{Free Deposit and Withdrawal on Personal Account at Different Cities}

In ideal status, Time Bank can deposit and withdrawal time anywhere in China. For example, if the user has service demand in Beijing in the future, the time currency exchanged for his labor value in Nanjing can be withdrawn successfully. Universal deposit and withdrawal allow users to deposit money and provide service to earn time currency without restrictions. This idea of saving time reflects the feature of deferred payment of labor achievements and users can continuously store time by creating value for other members. When they need help, they can state their own needs, and then accept the required services provided by other members, and ensure that everyone can fairly enjoy the return. 


\section{Difficulties in the Development of "Time Bank" Mutual-Support Mode}

"Time Bank", as a representative mode of mutual support for the aged, also has the same problems as the mode of mutual support for the aged analyzed above, including lack of legal and regulatory constraints, difficulties in risk prevention and control, low social identification, etc. In addition, the "Time Bank" has some development difficulties due to its time storage characteristics.

\subsection{How to Measure Time Currency}

"Time Bank" found inspiration from traditional commercial banks, which deposit and withdraw "money" without direct commodity exchange. "Time Bank" is essentially a barter between time and time. Although it will also add value when stored in a bank, its value and scope of use are limited. In terms of the traditional commercial bank, the value of money is standard and uniform all over the world, so the value of currency can be easily measured by the actual amount of money, and this value is widely recognized if without regard to the change of value caused by different access times. However, the value of labor time is different. There are many factors that affect the value of labor time, including labor intensity, technical content and service attitude, etc. These factors will lead to the totally different value, which makes it easy to measure the currency unequally without a standard principle. If Time Bank cannot measure its value by a unified standard, it is hard for customers to trust the bank, thus losing the source of customers and affecting the sustainable development of the bank. If the effective work of customers cannot be reasonably recognized, or if customers with service needs cannot get services matching the value, the bank makes no sense.

\subsection{Time Money Supply Exceeds Demand}

When it comes to sustainable development, the supply and demand balance is an important factor affecting sustainable development. However, according to the current operation of Time Banks in the community pension system in China, there is a lot of time left, and few people withdraw time from it so the supply exceeds the demand all the time, which has left potential problems for the long-term development of Time Banks. Although China's commercial banks also have the problem of high savings rate, there is no credit crisis or serious inflation, high savings rate will not generally cause bank runs, thus affecting the operation of banks. In terms of the current situation of the mutual support mode, it has not attracted enough attention from the public, and the traditional concept of "supported by the son" is still deeply rooted in Chinese hearts, thus causing the phenomenon that few people withdraw time. However, it is undeniable that there is a correlation between the time deposit and withdrawal of the Time Bank, so if there is no demand for services, there will naturally be a lack of creation of labor value. Although time currency also accepts other labor value of voluntary services in communities other than elderly care, the Time Bank will lose the essence 
of mutual support for the aged if things continue this way.

On the other hand, although time money supply exceeds demand now, China's aging rate is still increasing, and there will be more and more elderly people in need in the next decades. If a lot of withdrawal occurs at a certain point in the future, it will pose a threat to Time Banks which makes the bank unable to make ends meet. When people are generally unable to withdraw their deposited service time from the Time Bank, then Time Bank will not be able to run. If the bank cannot guide the masses to help the bank ensure a reasonable bank savings rate, the bank is vulnerable to go bankrupt.

\subsection{High Credit Risk}

Compared with traditional commercial banks, "Time Bank" does not have such strong credibility and be questioned by the public. As commercial banks play a significant role in the whole economy and cover a wide range of areas, there are a series of related systems for their establishment, operation, bankruptcy and financial supervision. Although commercial banks other than state-owned banks could fail, the deposits no more than 500,000 yuan can get the full amount of insurance compensation according to "Deposit Insurance Ordinance" if the bank goes bankrupt, which means that most customers" deposits can be guaranteed by the government (Yang, 2019). Strictly speaking, "Time Bank" is not a real bank, and it cannot be guaranteed by the state and the CBRC due to the lack of relevant supervision and management system. Most of Time Banks are operated by the community; the credibility and ability of the community organization are not enough to run it. There are so many unstable factors which affect the development of the bank, such as the change of community leadership, insufficient funds, and the reduction of volunteers. Time Bank has high credit risks for lack of system guarantee, and the time currency deposited may not be recognized in the future.

\subsection{The Limited Banking Business}

As far as the current situation is concerned, it is almost impossible for China's Time Banks to realize universal deposit and withdrawal network. Although Nanjing is currently conducting a citywide unified trial, it is hard to provide more services outside Nanjing. The elderly are likely to travel between different cities because of their children's work and family relationships. As far as the pilot process of a single bank is concerned, it cannot solve the problems well. There are so many constraints for the bank to branch out. First, the bank should operate in a wide range of areas. Second, it should be supported by technology and management. Specifically speaking, it requires a unified information management platform so that data is shared in a timely manner and even some business of state-owned commercial banks cannot be handled in different places, so it puts forward higher requirements for network technology and regulatory system. Finally, the currency value should always be standard and uniform in dif- 
ferent regions and different banks.

In addition to universal deposit and withdrawal, customers will also have the necessary requirements for transfer and inheritance. If time currency is exclusive, accompanying one's entire life and becoming invalid after death, the bank will be losing costumers and against the original intention for the convenience. In terms of transfer and inheritance, traditional currency has many relevant laws and regulations, and customers can use the law to protect their legitimate rights and interest. However, it is difficult to set a reasonable standard for time currency to be transferred and inherited.

To sum up, Time Bank can hardly meet the above conditions. As the practice subject of Time Banks, each community is relatively independent. Specifically, besides the bank's business, the scope of work is not intersected with each other due to cost and management reasons for communities in charge of the bank, it is difficult to realize the joint network of the whole region or the whole country. However, to realize the universal deposit and withdrawal of time currency in a wider range, we must overcome these disadvantages. Only by realizing the universal deposit and withdrawal of time currency can we attract more customers and achieve a wider coverage.

\section{Counter Measures to Promote the Development of "Time Bank"}

\subsection{Establish and Perfect the Relevant Legal System}

National legislation is the most effective and fundamental method to solve many problems. "Time Bank" is restricted in many aspects because it lacks the restriction and protection of relevant laws and regulations. Foreign countries generally pay more attention to policy making; that is, policies and regulations are first made before practice. On the contrary, China usually practices when laws and regulations are not perfect yet. And Time Banks have been practicing in China for 20 years, but China has not regulated and guaranteed it from the legislative level yet. If the relevant legal system can be established in a short time, the risk prevention and control mechanism, the punitive measures on dishonesty behavior, responsibilities of regulatory authorities and compensation standards of the Time Bank will be specified, and customers will be more confident about the operation of the bank, and the operation of the bank will be more efficient at the same time.

\subsection{Formulate a Unified Time Currency Measurement Mechanism}

Banks work around the function of currency, and Time Bank dose the same, but the form of currency is time, so time currency needs to be effectively measured. Because the standard of measurement is the value created by labor, it is difficult to measure it by a single standard. It is necessary to make a unified and perfect measurement mechanism in terms of technical content, service duration and user satisfaction, so users can serve others wholeheartedly and enjoy the service 
deserved.

Labor can be divided into simple labor and complex labor in the economic sense which means when measuring the value of commodities; it is measured by simple labor so complex labor has to be converted into simple labor. As it is difficult to measure the quality of service itself, we need to divide the services that may be involved into different grades according to the required labor intensity and skills, and different grades of services shall be measured according to different grades of conversion factors. When classifying different service types, it is necessary to be objective and fair to consider the degree of service difficulty, analyze factors including environment, psychology, risks comprehensively and classify different service types into different grades of range system. For the same type of service, the evaluation factor system under this type should be established to score the service quality objectively and fairly, so as to determine the value of labor time.

\subsection{Raise the Overall Level of "Time Bank"}

If "Time Bank" wants to improve its credibility and gain public recognition, it also needs to adjust the implementation subject of it. Judging from foreign practice, the overall level of Time Bank is much higher than that of China. For example, the "Time Bank" in Britain and the United States have set head offices, and the "Time Banks" in all districts have to accept the unified management of the head offices. This is not only conducive to the public's trust in Time Bank, but also conducive to the nationwide universal deposit and withdrawal of time currency. As far as the community is concerned, it is far from enough to establish the status of Time Banks. In fact, the community does not have the perfect conditions to manage and operate a bank. Although Time Bank is a non-profit organization with public welfare, it is necessary to fundamentally improve its current embarrassing situation, raise the level of the overall planning department, and interfere and supervise its operation from the government level. "Time Bank" can first try to coordinate relevant departments in a certain district; then extend to the whole city, finally the whole country layer by layer. The most important thing is to realize the sharing of resources.

\subsection{Perfect the Operation Mechanism of "Time Bank"}

In order to effectively prevent risks during the operation of the "Time Bank", especially the risk of deferred payment, it is necessary to optimize and innovate the implementation plans for the deposit, withdrawal, transfer and inheritance and strengthen cooperation with volunteer organizations, community-related institutions, enterprises, commercial banks, etc. The bank should establish a unified information platform which can share information resources, set up a service network, perfect punishment measures for breach of contract based on the realization of universal deposit and withdrawal, formulate specific rules of conduct for transactions so as to set up good enterprise image. Meanwhile, the bank 
should establish rewards and punishments mechanism, which is conducive to the improvement of service quality and service professionalism.

\section{Conflicts of Interest}

The author declares no conflicts of interest regarding the publication of this paper.

\section{References}

Chen, J. H. (2020) Difficulties and Countermeasures in the Development of Time Bank's Mutual Pension Model-Based on the Theoretical Perspective of Positive Aging (pp. 68-74). Nanjing: Jiangsu Social Sciences

Li, H. J., Li, W. J., \& Li, R. (2020) Research on China's Future Pension Model-An EXpansion Path Based on Time Bank (pp. 36-90). Beijing: Management world.

Yang, H. Y. (2019) Analyzing the Dilemma of "Time Bank" from the Perspective of Commercial Banks (pp. 128-130). Harbin: Economic Research Guide. 